\title{
COMMENT
}

\section{Every cloud: how the COVID-19 pandemic may benefit child health}

\author{
Damian Roland ${ }^{1}$ and Brian K. Stansfield ${ }^{2}$ \\ Pediatric Research (2021) 89:413-414; https://doi.org/10.1038/s41390-020-0947-x
}

\section{"In the midst of every crisis, lies great opportunity", Albert Einstein}

The SARS-COV-2 (COVID-19) pandemic has profoundly affected the world with millions of persons infected and nearly 200,000 deaths worldwide as of April 2020. In particular, health services worldwide have witnessed extremes with some overwhelmed by the sudden influx of acutely ill patients while other are temporarily contracted or even closed. To date, limited reports suggest that children are largely spared from the most profound effects of COVID-19 infection. ${ }^{1,2}$ The same cannot be said for the healthcare community tasked with caring for children who have experienced extensive service reconfiguration or have been redeployed to adult services.

The response of the healthcare community to COVID-19 is breathtaking and the ingenuity birthed from this crisis is worthy of our admiration. ${ }^{3}$ Since the first report of COVID-19 in December 2019, the pathogenicity of the SARS-COV-2 virus has been identified and verified, ${ }^{4}$ randomized trials for a variety of treatments have been completed, ${ }^{5}$ deep learning is able to distinguish COVID-19 from other pulmonary infections using radiographic studies, ${ }^{6}$ industries have been transformed to produce "in demand" medical supplies, ${ }^{7}$ and at least five candidate vaccines have entered phase I clinical trials. ${ }^{8}$ The speed with which these accomplishments have been reported is required to meet the acute demands of the pandemic.

Taking a long-term view of COVID-19 during the acute phase of the disease may prove difficult. As Henry Ford put it, "Had I asked people what they wanted, they would have said faster horses". However, the COVID-19 pandemic has brought several shortcomings of the current healthcare delivery infrastructure into focus and energized long-sought changes to bear a new reality.

Separating sick from well has always been implicit in pediatrics, but how we may do that in the future is worth considering. Remote screening using telehealth or digital applications is efficient, pragmatic, and simple. More importantly, automation and simplification allows healthcare providers to focus attention on the more immediate or complex needs of their patient population. Through necessity, digitally enabled care becomes an indispensable tool for seeing the masses and will likely take its place as a permanent fixture in pediatric healthcare akin to the examination room. Physicians and healthcare givers must now contemplate which encounters warrant face-to-face evaluation and which may be handled through electronic mediums. COVID19 brings us the opportunity to transition from "Is this technology needed?" to "How and when should it best be used?".
In the same vein, telehealth allows the pediatrician to triage minor contagious illnesses more efficiently and confidently while allowing the ill child to remain at home. Perhaps as important, the added reassurance to the parent or caregiver that their concerns have been heard and seen allows them to make better decisions about school attendance, absence from work, and consumption of more costly healthcare resources. ${ }^{9}$ For the pediatrician, telehealth provides additional flexibility by scheduling virtual visits throughout the work day or after hours. The recent decision by the Center for Medicare and Medicaid Services and some private payers to reimburse pediatricians for telehealth removes the financial barriers that limited the widespread adoption of virtual healthcare in the past. ${ }^{10}$

For the pediatric hospitalist or specialist, the limitations on care in the COVID-19 pandemic forced many long-held traditions to be abandoned. Rounding has long served as the centerpiece of medical education, but social distancing and the availability of personal protective equipment demands that rounds look different. Smaller teams and limited contact with potentially contagious children under the influence of COVID-19 may benefit both the learner and the patient. Remote rounding using virtual platforms may allow greater numbers of learners to participate in the care of children with rare or interesting findings without overwhelming the space. These suggestions are not new, but they may now be realized. ${ }^{11}$

Similarly, virtual learning may entice resourceful societies and institutions to embrace virtual conferences or lectureships. The recent cancellation of the 2020 Pediatric Academic Societies Meeting and other scientific meetings left much preparation unrealized and will hamper the flow of ideas that arise from these conferences. The lost opportunity to present and witness original science is disheartening. In addition, the individual and corporate costs associated with conference organization and attendance are substantial. The creation of true virtual conferences or the use of platforms to stream content from "in person" conferences offers an exciting alternative that warrants consideration. Several organizations have taken up this mantle using webinars, which may finally find its place after years of prompting.

Finally, administrative burden represents a tremendous barrier to the pandemic response and was quickly and largely abandoned. At both the local, state, and national level, small groups with decision-making authority were quickly created to lead us through the crisis and nimbly respond to various healthcare needs. These groups are able to receive and process information for immediate feedback to the healthcare system and facilitate the pooling and distribution of resources to have their greatest effect. It is no secret that the number of administrative 
positions in healthcare has greatly outpaced care providers and administrative burden is a dissatisfier for physicians and other healthcare workers. $^{12}$

The cost of the COVID-19 pandemic will be substantial to individuals, healthcare systems, and government entities. Perhaps, lessons learned from the COVID-19 pandemic will allow healthcare systems to refocus on delivering high-quality and efficient care. Returning to the previous state of healthcare would be a failure to recognize the ingenuity born out of this crisis.

\section{ADDITIONAL INFORMATION}

Competing interests: The authors declare no competing interests.

Publisher's note Springer Nature remains neutral with regard to jurisdictional claims in published maps and institutional affiliations.

\section{REFERENCES}

1. Liu, W. et al. Detection of Covid-19 in children in early January 2020 in Wuhan, China. N. Engl. J. Med. 382, 1370-1371 (2020).

2. $\mathrm{Xu}, \mathrm{Y}$. et al. Characteristics of pediatric SARS-CoV-2 infection and potential evidence for persistent fecal viral shedding. Nat. Med. 26, 502-505 (2020).
3. Woolliscroft, J. O. Innovation in response to the COVID-19 pandemic crisis. Acad. Med. https://doi.org/10.1097/ACM.0000000000003402 (2020). [Epub ahead of print].

4. Yan, R. et al. Structural basis for the recognition of SARS-CoV-2 by full-length human ACE2. Science 367, 1444-1448 (2020).

5. Cao, B. et al. A trial of lopinavir-ritonavir in adults hospitalized with severe Covid19. N. Engl. J. Med. 382, 1787-1799 (2020).

6. Li, L. et al. Artificial intelligence distinguishes COVID-19 from community acquired pneumonia on chest CT. Radiology https://doi.org/10.1148/radiol.2020200905 (2020).

7. Ranney, M. L., Griffeth, V. \& Jha, A. K. Critical supply shortages-the need for ventilators and personal protective equipment during the Covid-19 pandemic. $N$. Engl. J. Med. 382, e41 (2020).

8. Thanh Le, T. et al. The COVID-19 vaccine development landscape. Nat. Rev. Drug Discov. 19, 305-306 (2020)

9. McConnochie, K. M. et al. Telemedicine reduces absence resulting from illness in urban child care: evaluation of an innovation. Pediatrics 115, 1273-1282 (2005).

10. Hollander, J. E. \& Carr, B. G. Virtually perfect? Telemedicine for Covid-19. N. Engl. J. Med. 382, 1679-1681 (2020).

11. Reece, A. \& Klaber, R. Maximising learning on ward rounds. Arch. Dis. Child Educ. Pr. Ed. 97, 61-67 (2012).

12. Kocher, R. The downside of health care job growth. Harv. Bus. Rev. https://hbr.org/ 2013/09/the-downside-of-health-care-job-growth (2013). 